SUBMITTED TO: 4th International Conference on Synchrotron Radiation Instrumentation Manchester, England July 15-19,1991

\title{
Diagnostic Phosphors for Photon Beams at the ALS and APS *
}

Deming Shu*, Tony Warwick and Erik D. Johnson**

Lawrence Berkeley Laboratory, Berkeley, CA 94720, USAC7

-Argonne National Laboratory, Argonne, IL 60439, USA

*Brookhaven National Laboratory, Upton, NY 11973, USA

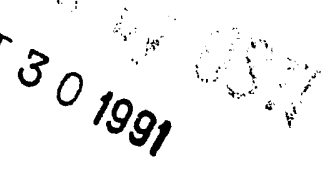

Some tests have been made of phosphors for photon beam diagnosis. Plasma sprayed coatings were checked for damage and decay during a period of several ampere-hours of irradiation from the NSLS Xray ring. Surface temperatures were measured and extrapolated to give an indication of the temperatures expected in more powerful photon beams. Based on our findings we have chosen plasma-sprayed coatings of Europium-doped Yttrium Oxide as the best candidate for use on masks and flags in 'white' photon beams of the new facilities.

\section{Introduction}

Plasma-sprayed ceramic coatings on metal are known to be resilient, and compatible with ultra-high vacuum.

We have plasma-sprayed three ceramic phosphor powders (emitting blue, green and red light) onto copper sample pieces and tested them in an undulator beam (X13) and in a wiggler beam (X17) at the National Synchrotron Light Source. We have evaluated the color of the visible light, the surface temperature during irradiation in UHV and looked for damage to the phosphor after exposure to the beam.

\section{Materials and coating}

Phosphor powders designed for use in color televisions were purchased from GTE Sylvania [1]. Three powders were tested:

1) Copper and silver activated zinc sulfide (P31) emitting green light.

2) Silver activated zinc sulfide (P22) emitting blue light.

3)Europium activated yttrium oxide (P22) emitting red light

\section{MASTER}

Figure 1, provided by GTE, shows the photon wavelengths below which the phosphors begin to respond and the wavelengths at which they emit.

*Work Performed under the auspices of U.S. Dept. of Energy, under Contract DE-AC02-76CH00016

Copper sample pieces were coated with these materials by a commercial plasma-coating company [2]. The plasma spray process involves blasting the 
surface of the copper samples with alumina powder, for roughening, followed by plasma spray of the phosphor. We specified a single pass of the spraying head, and obtained a coating of typically $15 \mu \mathrm{m}$ thickness, appearing barely opaque.

Vacuum properties were good. There was no measurable contribution from the samples $\left(4 \mathrm{~cm}^{2}\right)$ to the base pressure $\left(9 \times 10^{-10}\right.$ Torr $)$ of our $4^{\text {" diameter }}$ beamline chamber. Samples were also baked to $400^{\circ} \mathrm{C}$ in a vacuum furnace and showed no effects.

\section{Color of visible light}

A series of tests were carried out at $X 13$, which is a ten period undulator on the Brookhaven Xray ring. The samples were placed $15 \mathrm{~m}$ from the source and the undulator beam was approximately $0.75 \mathrm{~cm}$ in diameter at this point. The undulator gap was set to give $K=1.65$ resulting in 30 Watts of beam power. Bend magnet radiation was present on either side of the undulator beam.

Incident on an uncoated sample, the bend magnet light has a visible component with a blue color. For this reason we preferred the red or green phosphor over the blue emitter and we will not consider the blue further. We particularly preferred the red $P 22$, because it responds only to photons at UV wavelengths, and shorter. All of the phosphors were excited by the bend magnet radiation and they were excited so brightly in the center of the undulator beam that filters were needed in order to observe the light with a TV camera.

\section{Surface temperature}

We employed a commercially available infrared telescope [3] to view the surface of the phosphor during irradiation.

By choosing a device operating at $5 \mu \mathrm{m}$ wavelength we could measure through a commercially available sapphire window. Bench tests allowed us to obtain a correction to the measured infrared intensity for the absorption of the window, which was a factor of the order of $15 \%$. The dark current from the infrared detector in the telescope corresponded to a base temperature of

sut $50^{\circ} \mathrm{C}$.

The undulator produced a power density on the samples (mounted with the surface-normal at $30^{\circ}$ to the beam direction) of about $0.5 \mathrm{Wmm}^{-2}$ with $200 \mathrm{~mA}$ of electron current in the storage ring. The copper sample pieces were fastened to a large piece of copper acting as a heat sink. Upon irradiation, the temperature of the phosphor surface were seen to rise immediately to 80 or $90^{\circ} \mathrm{C}$. Extrapolating to the ALS, where the phosphors will 
be coated on a water cooled grazing incidence $\left(18^{\circ}\right)$ copper surface $15 \mathrm{~m}$ from the source, and irradiated by undulator beams giving power densities on the surface up to about $2 \mathrm{Wmm}^{-2}$, we anticipate local temperatures on the ceramic surface up to about $300^{\circ} \mathrm{C}$.

\section{Damage and light output}

Light output from the red and green phosphors was monitored by means of an imaging, color sensitive, light meter [4]. We made readings over a period of 48 hours of continuous irradiation in UHV at X13. Motion of the electron beam in the storage ring was the principle source of noise in these measurements. Figure 2 shows the results. The red P22 showed no significant change in efficiency. This was verified by moving the sample after the measurement so that a fresh piece of surface was illuminated, the light output was not affected. The green P31 showed indications of loss of efficiency after irradiation $(20 \%)$, and when a fresh part of the surface was irradiated the original efficiency was recovered.

Visual inspection of the phosphor after irradiation showed the red P22 to be clean. The green P31 and the blue P22 showed marks where the beam had been incident.

Further tests were carried out in a beam of hard $x$-rays from the super-conducting wiggler. During these tests the wiggler field was set to $4.4 \mathrm{~T}$, resulting in a critical photon energy of $18.58 \mathrm{keV}$. The red and blue phosphor ceramic coatings were exposed in the $X 17 \mathrm{~b}$ hutch, in air and without cooling. The samples were illuminated by the wiggler white beam, downstream of the exit beryllium window, with surface-normal at $45^{\circ}$, and about $3.5 \mathrm{Wmm}^{-2}$ surface power density. The exposure lasted 1 to 2 hours. The sample fluorescence flux and color were measured with the 'chromameter' [4]. The results show that the P22 red provided about 25 times higher visible fluorescence flux than the P31 green. The red exhibited flat flux response versus exposure time. The P31 fluorescence flux decreased rapidly during the first several minutes of exposure by about $50 \%$, then leveled off.

\section{Acknowledgement}

Thanks are due to the members of the Beamline Research and Development Group at the National Synchrotron Light Source for their hospitality during these tests, and to Dr. Dean Chapman for his help at X17b.

This work was supported by the Director, Office of Energy Research, Office of Basic Energy Sciences, Materials Sciences Division of the U.S. Department of Energy, under Contract No. DE-AC03-76SF00098 and Contract No. W-31-109-ENG-38.12 


\section{References}

[1] GTE Products Corp., Chemical and Metallurgical Division, 6505 E. Gayhart St., Commerce, CA 90040

[2] Plasma Coating Corp., 15331 S. Avalon Blvd., Gardena, CA 90248

[3] M67S from Mikron Instrument Co. Inc., 445 W.Main St, Wyckoff, NJ 07481

[4] "Chromameter" from Minolta Corp., 30,2-Chome, Azuchi-Machi, Higashi-Ku, Osaka 541, Japan

\section{Figure Captions}

1. Excitation functions and emitted spectra, versus photon wavelength, for the three phosphors (after GTE Sylvania).

2. Light output efficiency during irradiation at X13.

\section{DISCLAIMER}

This report was prepared as an account of work sponsnred by an agency of the United States This report was prepared as an accountes Governmert nor any agency thereof, nor any of their Government. Neither the United States Government nor any agency thereof, nor any of their bility for the accuracy, completeness, or usefulness of any information, apparatus, product, or bility for the accuracy, completeness, or usefulness of any information, apparatus, product, or process disclosed, or represents that its use would not infringe privately owned rights. Reference herein to any specific commercial product, process, or service by trade name, trademark, manufacturer, or otherwise does not necessarily constitute or imply its endorsement The views mendation, or favoring by the United States Government or any agency thereof. The views United States Government or any agency thereof. 
Typical Excitation Spectrum
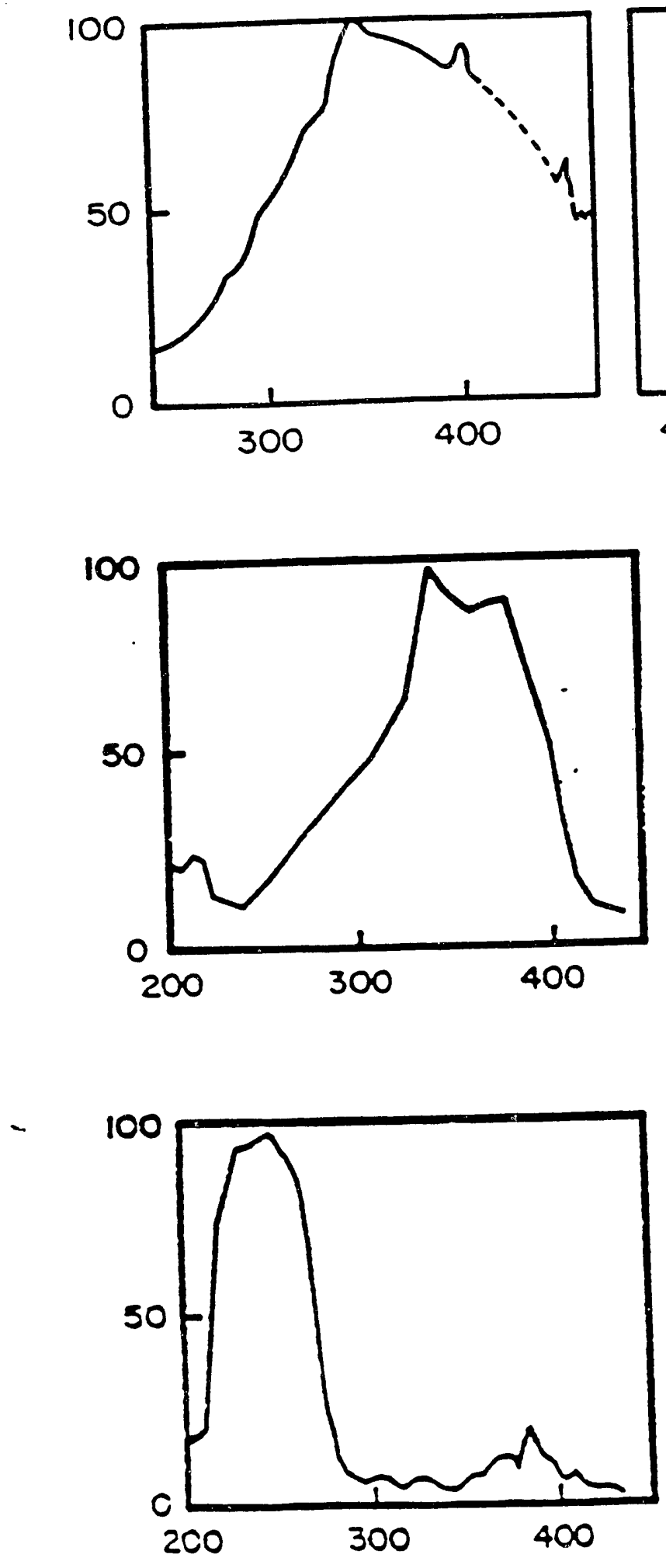

Typical Emission Spectrum
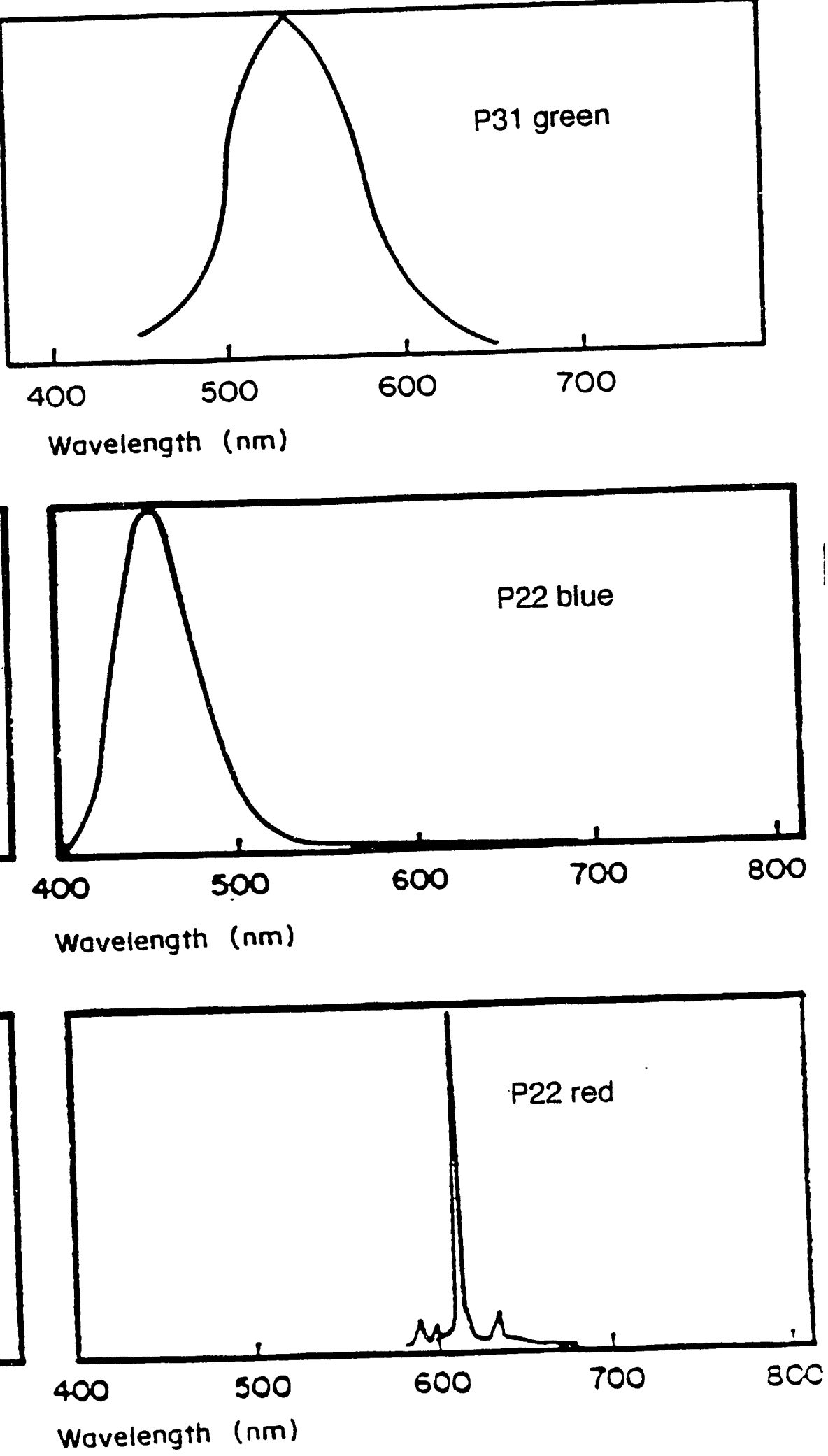

Figure !. 


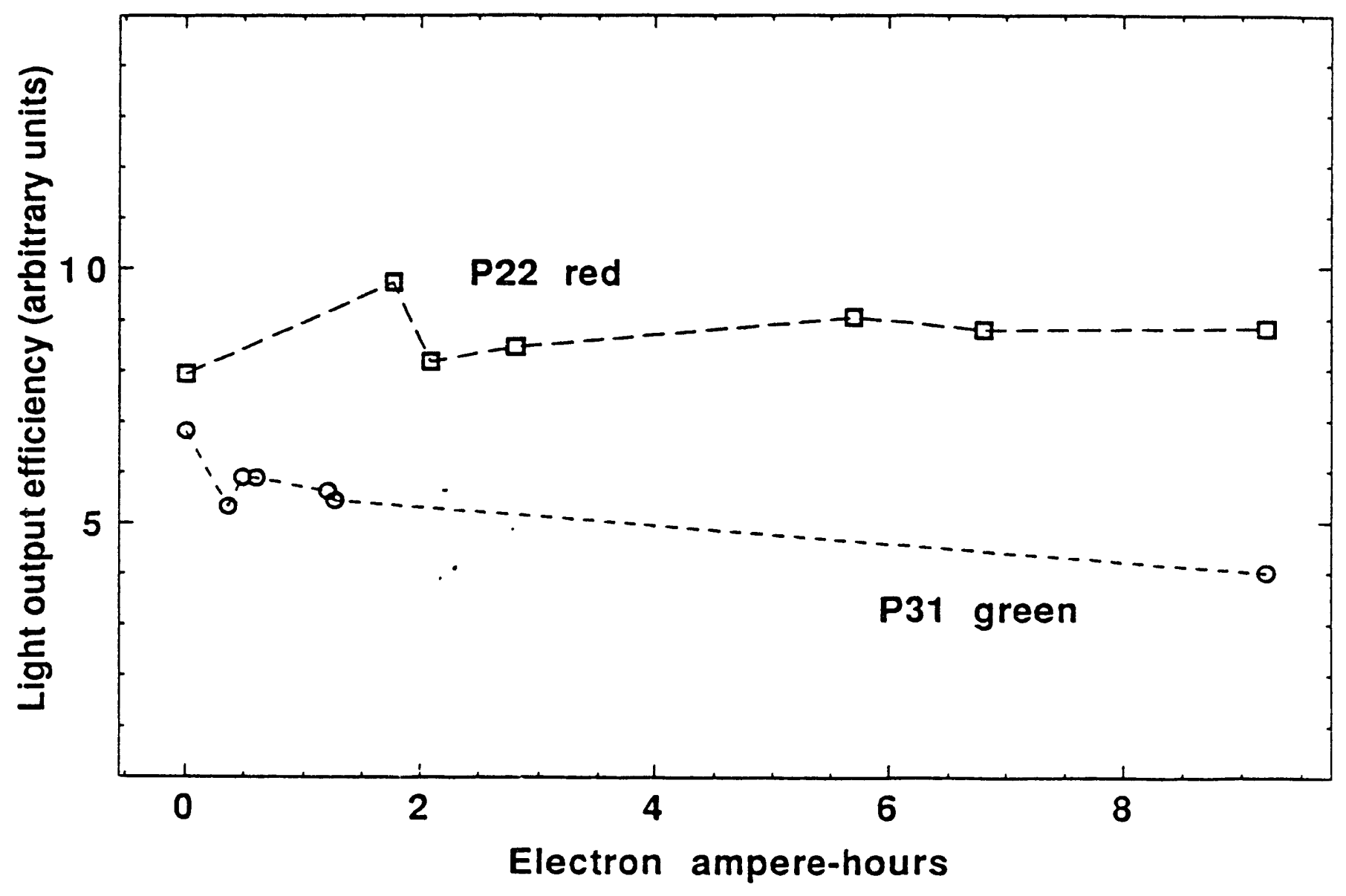

Figure 2. 

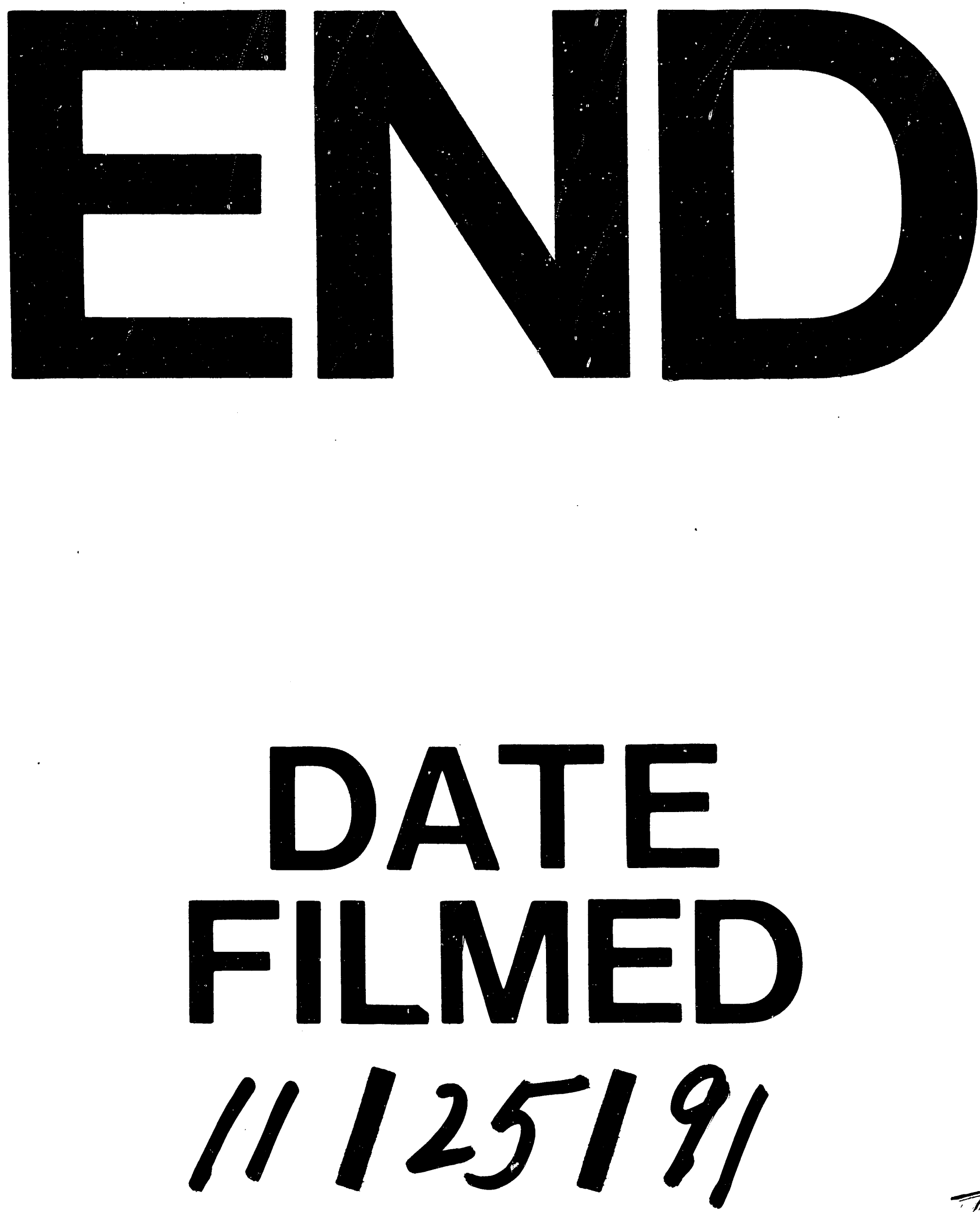
